\title{
Physical and Electrolytic Properties of Different Cyclic Carbonates as Solvents for Electric Double-Layer Capacitors
}

\section{Noritoshi NAMBU, * Dan KOBAYASHI, and Yukio SASAKI}

Department of Life Science and Sustainable Chemistry (Former name: Department of Nanochemistry), Faculty of Engineering, Tokyo Polytechnic University, 1583 Iiyama, Atsugi, Kanagawa 243-0297, Japan

* Corresponding author: nanbu@chem.t-kougei.ac.jp

\section{ABSTRACT}

Propylene carbonate (PC) is commonly used as a single solvent for electric double-layer capacitors (EDLCs). Trimethylene carbonate (TMC) and PC are isomeric with each other: structural isomerism, which is especially called metamerism. TMC has a six-membered ring and is solid below $48^{\circ} \mathrm{C}$. The relative permittivity of a PC-TMC equimolar binary mixture was highest in the four systems of solvents: PC-TMC $>$ PC-ethylene carbonate $($ EC) $>$ PC $>$ buthylene carbonate (BC). Despite the lower ionic conductivity, the use of a tetraethylammonium tetrafluoroborate $\left(\mathrm{TEABF}_{4}\right)$ solution in PC-TMC increased gravimetric capacitance of a coin cell. TMC may weaken solvation of electrolyte ions, and the electrolyte ions can closely approach the electrode in a compact double layer.

(c) The Electrochemical Society of Japan, All rights reserved.

Keywords : Cyclic Carbonate, Structural Isomerism, Relative Permittivity, Capacitance

\section{Introduction}

Electric double-layer capacitor (EDLC) is an energy storage device that accumulates electric charges in the electrified interphase between an activated carbon electrode and an electrolyte. ${ }^{1}$ Propylene carbonate (PC or 4-methyl-1,3-dioxolan-2-one) is commonly used as the single solvent for the EDLCs. PC has a five-membered ring with a methyl group. Trimethylene carbonate (TMC, 1,3-dioxan-2one, or 1,3-propylene carbonate) is a six-membered cyclic carbonate ester. TMC and PC are isomeric with each other: structural isomerism, which is especially called metamerism. The physical chemistry of TMC and ethylene carbonate (EC or 1,3-dioxolan-2-one) appears to share similarities, but also exhibit differences. The same is true for the physical chemistry of PC and buthylene carbonate (BC or 4ethyl-1,3-dioxolan-2-one). $\mathrm{EC}$ has a five-membered ring and is solid below $36.37^{\circ} \mathrm{C} .^{2} \mathrm{TMC}$ is solid below $48^{\circ} \mathrm{C}$. Very little is known about the physical and electrolytic properties of TMC and its application to EDLCs. BC has a five-membered ring with an ethyl group. $\mathrm{PC}$ and $\mathrm{BC}$ are liquids at room temperature. Although $\mathrm{BC}$ and its analogues (alkylated cyclic carobnates) are highly viscous, they show great durability of oxidation. ${ }^{3,4}$

We previously reported that the use of fluoroethylene carbonate (FEC) as a single solvent increased capacitance of EDLCs. ${ }^{5}$ In the present paper, we describe the effect of different structures on the physical and electrolytic properties of cyclic carbonates: PC, TMC, $\mathrm{EC}$, and $\mathrm{BC}$. The relative permittivities, molar concentrations, viscosities, and ionic conductivities of the solvents or the electrolytic solutions are shown as a function of temperature. Furthermore, we have evaluated the performance of EDLCs. Figure 1 shows the structures of $\mathrm{PC}, \mathrm{TMC}, \mathrm{EC}$, and $\mathrm{BC}$.

\section{Experimental}

\subsection{Materials}

We synthesized TMC from 1,3-propanediol (1 mol, $76 \mathrm{~g}$ ) and dimethyl carbonate (DMC) $(1 \mathrm{~mol}, 90 \mathrm{~g})$ in the presence of sodium hydroxide $(1 \mathrm{~mol}, 40 \mathrm{~g})$ in a yield of about $40 \%$. TMC was purified under reduced pressure first by simple distillation and then by fractional distillation. The purity of TMC was determined to be more

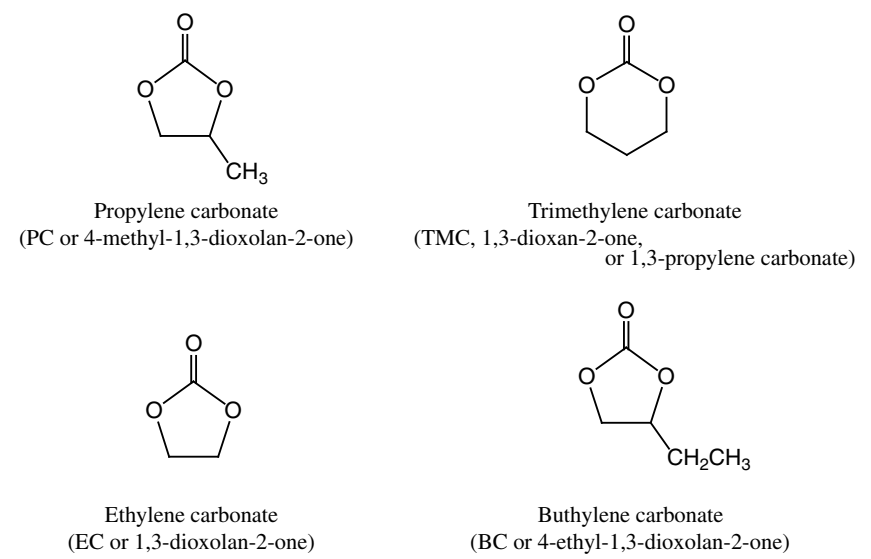

Figure 1. Structures of $\mathrm{PC}, \mathrm{TMC}, \mathrm{EC}$, and $\mathrm{BC}$.

than $99.7 \%$ by the use of gas chromatograph equipped with a FID detector (Shimadzu Corp., GC-1700). PC, BC, and tetraethylammonium tetrafluoroborate $\left(\mathrm{TEABF}_{4}\right)$ were used as received (LBG and CPG of Kishida Chemical Co., Ltd.). TMC can be also prepared from 1,3-propanediol and ethyl chloroformate, or from oxetane and carbon dioxide with an appropriate catalyst. ${ }^{6}$

\subsection{Apparatus and methods}

We have investigated the temperature $(\theta)$ dependence of relative permittivities $\left(\varepsilon_{\mathrm{r}}\right)$ of solvents and that of mass densities $(d)$, viscosities $(\eta)$, and ionic conductivities $(\kappa)$ of electrolytic solutions. $\mathrm{TEABF}_{4}$ was used as the electrolyte. The molar concentration of $\mathrm{TEABF}_{4}$ was set to $1 \mathrm{~mol} \mathrm{dm}^{-3}$ in a PC single solvent, a PC-TMC equimolar binary mixture, and a $\mathrm{PC}-\mathrm{EC}$ equimolar binary mixture at $25^{\circ} \mathrm{C}$. Since the solubility of $\mathrm{TEABF}_{4}$ was lower in a $\mathrm{BC}$ single solvent, the molar concentration of $\mathrm{TEABF}_{4}$ was set to $0.5 \mathrm{~mol} \mathrm{dm}^{-3}$ at $25^{\circ} \mathrm{C}$.

The apparatus and techniques for measurement are essentially the same as those previously reported. ${ }^{7-10}$ Ionic conductivities of electrolytic solutions were measured by use of a conductometer (Toa Electronics, Model CM-60S) equipped with the cell (Model CGT-511B) over the temperature range of -5 to $70^{\circ} \mathrm{C}$. 
We have evaluated the charge and discharge characteristics of EDLCs. Activated carbon electrodes contained 83.0 mass\% activated charcoal (specific surface area: about $1700 \mathrm{~m}^{2} \mathrm{~g}^{-1}$, pore volume: about $0.75 \mathrm{~mL} \mathrm{~g}^{-1}$ ), 10.7 mass $\%$ conductor, 4.0 mass $\%$ dispersant, and 2.3 mass $\%$ binder. The performance of 2025-type coin cells (can size: $20 \mathrm{~mm}$ in diameter and $2.5 \mathrm{~mm}$ in thickness, stainless steel body) was investigated with a charge/discharge unit (ASKA, Model ACD-M01-05N). A separator (Celgard Inc., \#3501) was sandwiched between two identical-size activated carbon electrodes in the coin cells. The coin cells were charged in a constant current (CC) $\left(-0.6 \mathrm{~mA},-72 \mathrm{~mA} \mathrm{~g}^{-1}\right)$-constant voltage $(\mathrm{CV})(2.5 \mathrm{~V})$ regime at $25^{\circ} \mathrm{C}$ until total charge time reached $60 \mathrm{~min}$. Afterward they were discharged to $0 \mathrm{~V}$ at the inverse current.

\section{Results and Discussion}

\subsection{Relative permittivities of solvents}

Relative permittivity reflects the ease of progress of dielectric polarization. The relative permittivity has a significant effect on the strength of the interactions between ions in electrolytic solutions. Figure 2(a) shows the temperature $(\theta)$ dependence of relative permittivities $\left(\varepsilon_{\mathrm{r}}\right)$ of PC-TMC, PC-EC, PC, and BC solvents. The relative permittivities of the cyclic carbonates decreased gradually with an increase in temperature. The relative permittivity of PCTMC was highest in the four systems of solvents: PC-TMC > PC-EC $>$ PC $>$ BC. The cyclic nature of the carbonates precludes a trans configuration of the $\mathrm{O}-\mathrm{R}$ alkoxy groups with respect to the carbonyl group $(\mathrm{C}=\mathrm{O})$ and constrains the $\mathrm{O}-\mathrm{R}$ moieties to align in a planar geometry, a so-called cis configuration. ${ }^{11,12}$ The cis configuration results in the large electric dipole moment. The relative permittivity is governed by the dipole moment, the correlation between the dipoles, the molar concentration, etc. Conformations of TMC may be analogous to those of cyclohexane. Cyclohexane adopts chair, half chair, twist boat, and boat conformations. ${ }^{13,14}$ More than $99 \%$ of the cyclohexane molecules are estimated to be in a chair conformation at any given moment because of the greatest stability of the chair conformation. ${ }^{13}$ The strong correlation between the dipoles can cause aggregation of TMC in the chair conformation. The molar concentration of TMC was higher than those of PC and $\mathrm{BC}$, as described in the next paragraph. The synergistic effect of these factors resulted in the highest relative permittivity of PC-TMC. The large electric dipole moment of the TMC molecule may result from the vector addition of the individual bond moments in the chair conformation.
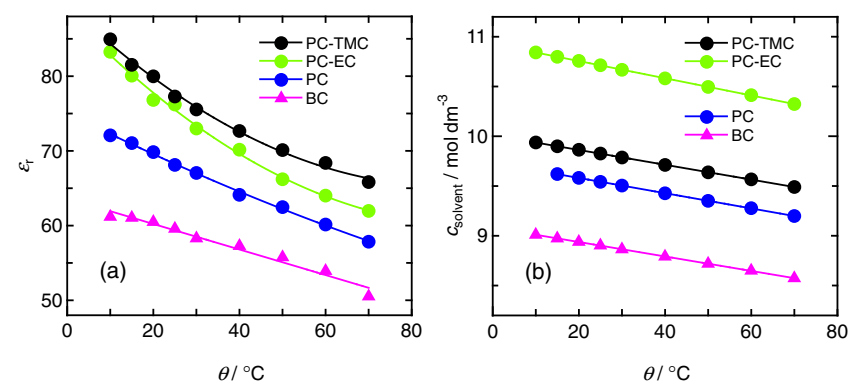

Figure 2. (Color online) (a) Relative permittivities $\left(\varepsilon_{\mathrm{r}}\right)$ of PCTMC, PC-EC, PC, and BC solvents and (b) molar concentrations $\left(c_{\text {solvent }}\right)$ of the solvents in $\mathrm{TEABF}_{4}$ solutions as a function of temperature $(\theta)$ from 10 to $70^{\circ} \mathrm{C}$. The molar concentrations of the solvents were calculated from Eq. (1). The molar concentration of $\mathrm{TEABF}_{4}$ in PC, PC-TMC, and PC-EC was set to $1 \mathrm{~mol} \mathrm{dm}^{-3}$ at $25^{\circ} \mathrm{C}$. The molar concentration of $\mathrm{TEABF}_{4}$ in $\mathrm{BC}$ was set to $0.5 \mathrm{~mol} \mathrm{dm}^{-3}$ at $25^{\circ} \mathrm{C}$ from the viewpoint of the solubility.

\subsection{Molar concentrations of solvents in electrolytic solutions}

Although both EC (fp $36.37^{\circ} \mathrm{C}$ ) and TMC (fp $48^{\circ} \mathrm{C}$ ) are solids below room temperature, the high molal depression of their freezing points makes it possible to prepare room-temperature electrolytic solutions. Figure 2(b) shows the temperature $(\theta)$ dependence of molar concentrations $\left(c_{\text {solvent }}(\theta)\right)$ of PC-TMC, PC-EC, PC, and BC in the electrolytic solutions. We used $\mathrm{TEABF}_{4}$ as a quaternary ammonium compound (QA) for EDLCs. The molar concentration of the solvent was calculated from the mass density of the solution $(d(\theta))$, the molar mass of the solvent $\left(M_{\text {solvent }}\right)$, the molar mass of QA $\left(M_{\mathrm{QA}}\right)$, and the molar concentration of $\mathrm{QA}\left(c_{\mathrm{QA}}\left(25^{\circ} \mathrm{C}\right)\right)$ according to the following equation:

$$
c_{\text {solvent }}(\theta)=\frac{d(\theta)}{d\left(25^{\circ} \mathrm{C}\right)} \cdot \frac{d\left(25^{\circ} \mathrm{C}\right)-M_{\mathrm{QA}} c_{\mathrm{QA}}\left(25^{\circ} \mathrm{C}\right)}{M_{\mathrm{solvent}}}
$$

The replacement of PC with EC or TMC increased the molar concentration of the solvent in the electrolytic solution: PC-EC > $\mathrm{PC}-\mathrm{TMC}>\mathrm{PC}>\mathrm{BC}$. The molar concentration of the solvent reflects both the strength of intermolecular attraction and the reverse of the molar volume. The high molar concentration of PC-TMC resulted from the synergistic effect of the strong dipole-dipole attractive force and the small molar volume. The molar concentration of $\mathrm{TEABF}_{4}$ in $\mathrm{BC}$ was as low as $0.5 \mathrm{moldm}^{-3}$ at $25^{\circ} \mathrm{C}$. Nevertheless, the largest molecular size of $\mathrm{BC}$ led to the lowest molar concentration of $\mathrm{BC}$ in the four systems of solutions. Except for PC-EC, the order of the relative permittivities of the solvents was in accord with that of the molar concentrations of the solvents.

\subsection{Viscosities of electrolytic solutions}

Viscosity is regarded as internal friction based on intermolecular forces and affects ionic conductivity of the electrolytic solution. Figure 3(a) shows the temperature dependence of viscosities $(\eta)$ of electrolytic solutions in PC-TMC, PC-EC, PC, and BC. The viscosities of the electrolytic solutions decreased rapidly with an increase in temperature. The high translational kinetic energy allows intermolecular attractions to be overcome more easily. The viscosities decreased in the following order: $\mathrm{PC}-\mathrm{TMC}>\mathrm{BC}>$ PC-EC $>$ PC. The highest viscosity of PC-TMC can be attributed to aggregation. Although the molar concentration of $\mathrm{TEABF}_{4}$ was as low as $0.5 \mathrm{~mol} \mathrm{dm}^{-3}$, the viscosity of the electrolytic solution in $\mathrm{BC}$ was higher than those in PC-EC and PC because of the largest molecular size of $\mathrm{BC}$.

We can liken the difference in internal friction between TMC and PC to that between cyclohexane and methylcyclopentane. Cyclohexane and methylcyclopentane are isomeric with each other. The molar volume of cyclohexane $\left(108.75 \mathrm{~cm}^{3} \mathrm{~mol}^{-1}\right.$ at $\left.25^{\circ} \mathrm{C}\right)$ is smaller than that of methylcyclopentane $\left(113.13 \mathrm{~cm}^{3} \mathrm{~mol}^{-1}\right.$ at $\left.25^{\circ} \mathrm{C}\right)$. However, the viscosity of cyclohexane $\left(0.898 \mathrm{mPas} \text { at } 25^{\circ} \mathrm{C}\right)^{2}$ is
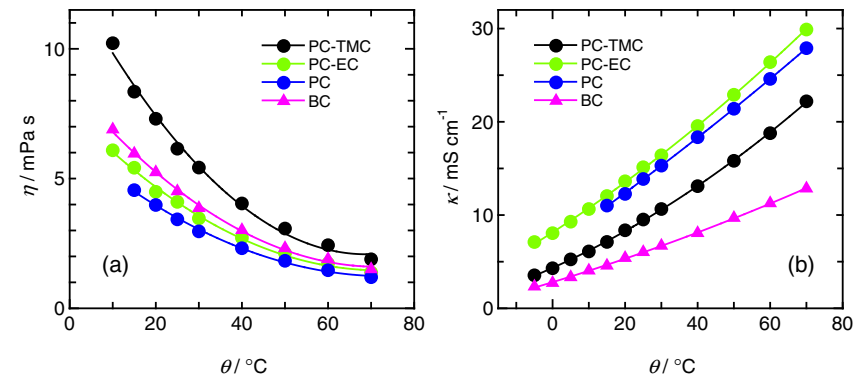

Figure 3. (Color online) (a) Viscosities $(\eta)$ of $\mathrm{TEABF}_{4}$ solutions in PC-TMC, PC-EC, PC, and BC as a function of temperature $(\theta)$ from 10 to $70^{\circ} \mathrm{C}$. (b) Ionic conductivities $(\kappa)$ of $\mathrm{TEABF}_{4}$ solutions in PC-TMC, PC-EC, PC, and BC as a function of temperature from -5 to $70^{\circ} \mathrm{C}$. Electrolytic solutions are the same as described in the caption of Fig. 2. 
higher than that of methylcyclopentane $\left(0.478 \mathrm{mPa}\right.$ s at $\left.25^{\circ} \mathrm{C}\right) .{ }^{2}$ The data mean that internal friction between six-membered rings is higher than that between five-membered rings with a methyl group.

\subsection{Ionic conductivities of electrolytic solutions}

Conductivity of a solution is a key factor determining the internal resistance and rate performance of EDLCs. Figure 3(b) compares the temperature $(\theta)$ dependence of ionic conductivities $(\kappa)$ of electrolytic solutions in PC-TMC, PC-EC, PC, and BC. The conductivities of the electrolytic solutions increased with an increase in temperature. This is because the viscosities decreased rapidly with an increase in temperature, as shown in Fig. 3(a). Although the replacement of PC with TMC or EC increased the viscosity of the electrolytic solution, the PC-EC solution was more conductive than the PC counterpart. In contrast, the PC-TMC solution was less conductive than the PC counterpart. The conductivities decreased in the following descending order: $\mathrm{PC}-\mathrm{EC}>\mathrm{PC}>\mathrm{PC}-\mathrm{TMC}>\mathrm{BC}$. The conductivity is affected by the ionic mobility, the charge numbers of the ions, the concentration of the electrolyte, the degree of ionic dissociation of the electrolyte, etc. The ionic mobility is related to the viscosity of the electrolytic solution. The degree of ionic dissociation of the electrolyte is set by the balance of the permittivity, Lewis acidity, and Lewis basicity of the medium, depending on the concentration of the electrolyte. The electron-pair donability of a solvent is a measure of the ability to solvate cations. The electron-pair donability of oxygen atoms of the OCOO moiety in TMC may be lower than that in $\mathrm{PC}$ and $\mathrm{EC}$ because of the steric hindrance between the six-membered rings. As a result, TMC may weaken solvation of electrolyte ions. The conductivity of the electrolytic solution in $\mathrm{BC}$ was lowest in the four systems of solutions. Although the molar concentration of $\mathrm{TEABF}_{4}$ was lower, the degree of ionic dissociation of $\mathrm{TEABF}_{4}$ in $\mathrm{BC}$ may be also lower than those in the other cyclic carbonates. In addition, the viscosity was higher in BC.

\subsection{Performance of EDLCs}

We evaluated integral full-cell capacitances per unit mass of activated carbon from discharge curves of 2025-type coin cells. Figure 4 shows the charge and discharge curves of the coin cells at $0.6 \mathrm{~mA}\left(72 \mathrm{~mA} \mathrm{~g}^{-1}\right)$ at $25^{\circ} \mathrm{C}$. The reciprocals of the slopes of the charge and discharge curves reflect the integral full-cell capacitances. The replacement of PC with TMC or EC increased the gravimetric capacitance during the discharge: $26.9 \mathrm{Fg}^{-1}$ for PCTMC, 26.0 $\mathrm{F} \mathrm{g}^{-1}$ for PC-EC, 25.5 $\mathrm{Fg}^{-1}$ for PC, and $24.6 \mathrm{~F} \mathrm{~g}^{-1}$ for $\mathrm{BC}$. The viscosity of the electrolytic solution in PC-TMC was higher than those in PC and PC-EC. Consequently, the conductivity of the electrolytic solution was lower in PC-TMC, as described in the previous section. Nevertheless, the capacitance found for PC-TMC was higher than those for PC-EC and PC. A very small distance between activated carbon electrodes in the coin cell can compensate for the lower ionic mobility of $\mathrm{TEABF}_{4}$ in the bulk of the PC-TMC solution. Furthermore, TMC may weaken solvation of electrolyte ions, and the electrolyte ions can closely approach the electrode in a compact double layer. The higher relative permittivity of PC-TMC may also contribute to increasing the capacitance in spite of the dielectric saturation in the electrified interphase between an activated carbon electrode and an electrolyte. The lowest capacitance found for $\mathrm{BC}$ was manifested by the lower concentration of $\mathrm{TEABF}_{4}$ and the lower conductivity of the electrolytic solutions.

\section{Conclusion}

We have investigated the effect of different structures on the physical and electrolytic properties of cyclic carbonates: TMC, EC, PC, and BC. Moreover, we evaluated the performance of EDLCs. The relative permittivity of PC-TMC was highest in the four systems of solvents: PC-TMC $>$ PC-EC $>$ PC $>$ BC. The replacement of
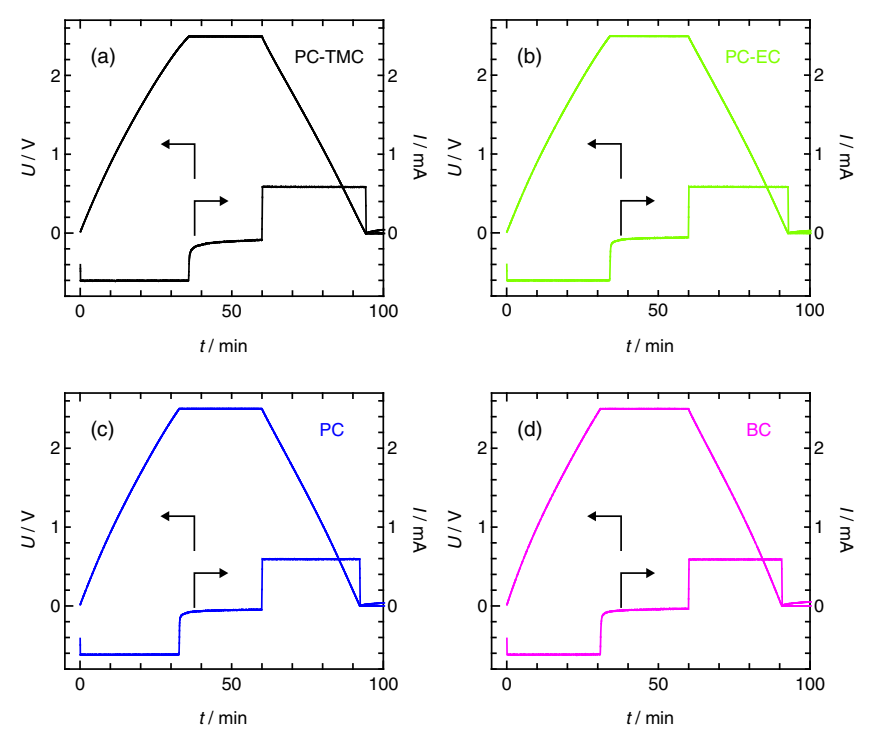

Figure 4. (Color online) Charge and discharge characteristics of 2025 -type coin cells at a cut-off voltages of $2.5 \mathrm{~V}$ at $25^{\circ} \mathrm{C}$. Electrolytic solutions: $1 \mathrm{~mol} \mathrm{dm}^{-3} \mathrm{TEABF}_{4}$ solutions in (a) PC-TMC, (b) PC-EC, and (c) PC and $0.5 \mathrm{~mol} \mathrm{dm}^{-3} \mathrm{TEABF}_{4}$ solution in (d) BC. The coin cells were charged from 0 to $2.5 \mathrm{~V}$ in a constant-current (CC) $\left(-0.6 \mathrm{~mA},-72 \mathrm{~mA} \mathrm{~g}^{-1}\right)$ mode and further charged to keep the constant voltage $(\mathrm{CV})$. Total charging time was set to $60 \mathrm{~min}$. The coin cells were then discharged to $0 \mathrm{~V}$ at $+0.6 \mathrm{~mA}$.

PC with $\mathrm{EC}$ or TMC increased the molar concentration of the solvent in a $\mathrm{TEABF}_{4}$ solution: $\mathrm{PC}-\mathrm{EC}>\mathrm{PC}-\mathrm{TMC}>\mathrm{PC}>\mathrm{BC}$. The viscosities of the electrolytic solutions decreased in the following order: $\mathrm{PC}-\mathrm{TMC}>\mathrm{BC}>\mathrm{PC}-\mathrm{EC}>\mathrm{PC}$. Internal friction between six-membered rings may be greater than that between fivemembered rings with a methyl group. The ionic conductivity of the electrolytic solution in PC-TMC was lower than those in PC and PC-EC. Nevertheless, the use of TMC-PC as a mixed solvent increased the gravimetric capacitance of a coin cell. It is very intriguing to investigate the rate capabilities of the EDLCs.

\section{References}

1. B. E. Conway, Electrochemical Supercapacitors, Kluwer Academic/Plenum Publishers, New York (1999).

2. J. A. Riddick, W. B. Bunger, and T. K. Sakano, Organic Solvents: physical properties and methods of purification, 4th ed., Wiley-Interscience, New York (1986).

3. M. Ue, Denki Kagaku (presently Electrochemistry), 66, 904 (1998). [in Japanese]

4. K. Chiba, T. Ueda, Y. Yamaguchi, Y. Oki, F. Saiki, and K. Naoi, J. Electrochem. Soc., 158, A1320 (2011).

5. N. Nanbu, K. Suzuki, N. Yagi, M. Sugahara, M. Takehara, M. Ue, and Y. Sasaki, Electrochemistry, 75, 607 (2007).

6. S.-H. Pyo, P. Persson, M. A. Mollaahmad, K. Sörensen, S. Lundmark, and R. Hatti-Kaul, Pure Appl. Chem., 84, 637 (2012).

7. N. Nanbu, T. Ebina, H. Uno, Y. Miyazaki, and Y. Sasaki, Electrochem. Solid-State Lett., 9, A482 (2006); Erratum, 10, S3 (2007).

8. N. Nanbu, T. Ebina, H. Uno, S. Ishizawa, and Y. Sasaki, Electrochim. Acta, 52, 1763 (2006).

9. N. Nanbu, M. Takehara, S. Watanabe, M. Ue, and Y. Sasaki, Bull. Chem. Soc. Jpn., 80, 1302 (2007).

10. N. Nanbu, S. Watanabe, M. Takehara, M. Ue, and Y. Sasaki, J. Electroanal. Chem., 625, 7 (2009).

11. L. A. Dominey, Lithium Batteries (Ed. G. Pistoia), Elsevier, Amsterdam, p. 143 (1994).

12. M. Salomon, H.-P. Lin, E. J. Plichta, and M. Hendrickson, Advances in LithiumIon Batteries (Eds. W. A. van Schalkwijk and B. Scrosati), Kluwer Academic/ Plenum Publishers, New York, p. 315 (2002).

13. T. W. G. Solomons and G. B. Fryhle, Organic Chemistry, 7th ed., John Wiley \& Sons, New York, p. 157 (2000).

14. K. P. C. Vollhardt and N. E. Schore, Organic Chemistry Structure and Function, 5th ed., W. H. Freeman and Company, New York, p. 139 (2007). 